Lupascu M., Comsa Gh. I.

\title{
Six year old with isolated sphenoidal mucocele and ophthalmopathy - a case report
}

"Ovidius" University of Constanta, Faculty of Medicine

\begin{abstract}
Sphenoid sinus affections in children are very rare occurrences due to the late development of the sinus and treatment may present quite a challenge even to the most skillful surgeon because of the small nasal fossae. Due to the often vague and uncharacteristic symptomatology sphenoid sinus disease is misdiagnosed and the treatment is delayed, sometimes with serious complications that are life threatening if not properly managed.

We present the case of a six year old patient with a mucocele affecting an unusually large sphenoid sinus with concomitant Graves-like ophthalmopathy that has been treated through functional endoscopic sinus surgery but also needed prolonged cortisonic treatment.
\end{abstract}

Keywords: sphenoid sinus, endoscopy, headache

\section{Lupascu Mihai}

Bld Ferdinand 53, Bl A8, Sc, B, Ap. 45 Constanta, Romania Tel.: +40745050439 , e-mail:dr_lupa@yahoo.com

\section{Introduction}

Sphenoid sinus affections in children younger than 7 years old are very rare occurrences [1], mainly due to the fact that the sphenoid sinus is the last of the sinuses to be developed, reaching almost its' adult dimensions after puberty.

The symptomatology that accompanies sphenoid sinusitis is very poor and often vague and misleading, headache being the most common symptom [2], therefore sphenoiditis is commonly misdiagnosed in up to $80 \%$ of cases [3]), many patients being treated for migraine or for trigeminal neuralgia for long periods of time, sometimes more than 2-3 months

The gravity of sphenoid sinus disease is given mainly by the very delicate structures that surround the sinus, the II, III, IV, V, VI and vidian nerves, the internal carotic artery inside the cavernous sinus and the pituitary gland $[3,4,5,7,8,9]$ and, although palsies or other perilesional inflammatory problems may exist at presentation, many of these complications would have a lower rate of occurrence with better diagnosis. 


\section{Case report}

A six year old boy presents with mild exophthalmia and small pterygium of the right eye, a history of 3 weeks of retroorbital pain, the child did not have a history of rhinorrhoea or nasal obstruction and blood count was within normal limits. He had been treated for the last week with broad-spectrum antibiotics and systemic cortical therapy with little results.

The MRI exam showed large sphenoid sinuses for that age $(20 / 22 \mathrm{~mm})$, the right sphenoid sinus being occupied in its entirety by thickened mucosa and fluid as seen in Figure 1 and 2.

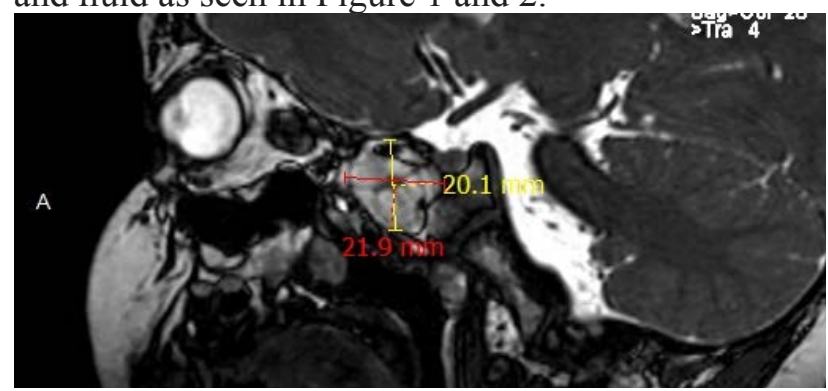

Figure 1 Dimensions of right sphenoid sinus in six year old patient with mucocele sagittal view

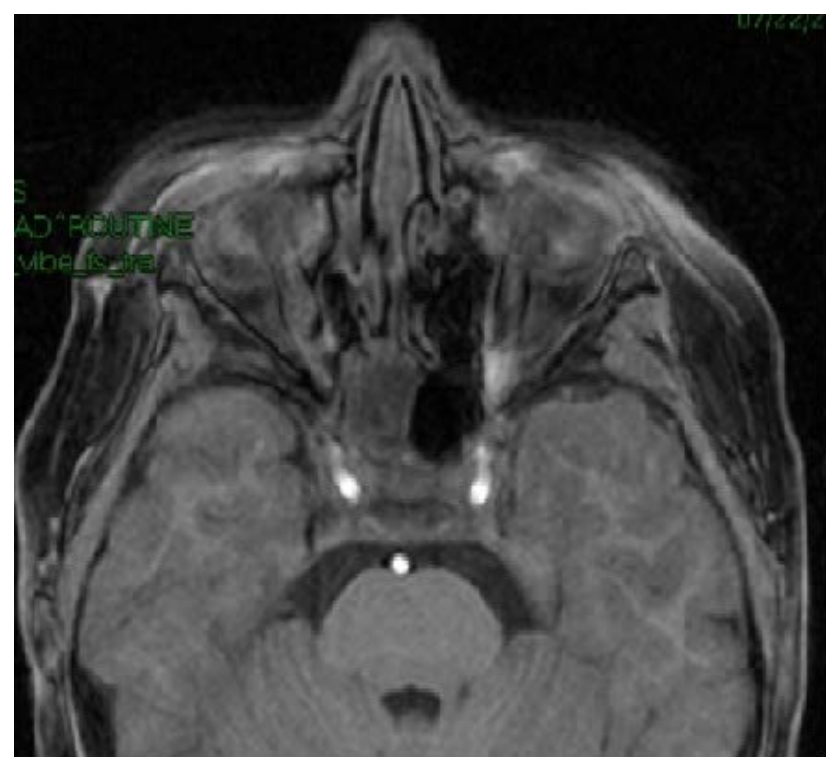

Figure 2 Axial view
The patient was operated on endoscopically, through a paranasal approach to the sphenoid sinus, the ostium was enlarged towards the medial, revealing the sphenoidal mass to be a degenerated, thickened mucosa with minimal mucus accumulation that was carefully stripped of the walls of the sinus. No dehiscence of the structures surrounding the sinus was found during the operation. Postoperatively the medical treatment was maintained for another 2 weeks in order to gradually decrease the dosage of steroidal anti-inflammatory medication. The headaches disappeared in a couple of days after surgery and swelling of the eye diminished.

After a couple of months the child returned with similar symptomatology, though, this time the MRI exam couldn't find any lesions in or around the orbit to explain the mild exophthalmia, the sinuses remained clear, the ophthalmological exam, apart from the pterygium that persisted did not find any cause of intraorbital pressure. Hormonal tests did not show any glandular dysfunctions.

A fine needle retro bulbar biopsy was performed in the neurosurgery department that revealed only diffuse inflammation without being able to mention the cause of edema. The steroidal treatment was reinstated with the alleviation of symptoms, yet for the next almost twelve months the child showed the same symptoms whenever the medication ceased pleading for the autoimmune nature of the illness. After almost a year, another attempt at lowering doses the dosage was made, by this time the child was showing cushingoid features, this final attempt being successful and the symptoms remained in remittance. The child achieved endocrine normalization and regained normal appearance.

\section{Discussion and Conclusions}

Sphenoidal isolated disease is a rare occurrence, less than $5 \%$ of sinusal disease in adults [10] and exceptional in children younger than 7 years $[7,8]$, though it should be considered in persistent 
headaches and sought after, headaches being the most common symptom usually retro orbital [11], but there have been series reported where the pain radiated to the occipital region or pain in the trigeminal nerve distribution $[1,2,3]$. Due to the development and more common use of CT and MRI investigations more recent studies show an involvement of more than $10 \%$ of the sphenoid sinus in sinusal pathology [10]. Undiagnosed sphenoid sinus disease holds a very high associated morbidity due to the very delicate structures that surround the sinus and once installed only some are remitted even with consecutive proper treatment [6].

The case raises several discussion points: Graves-like ophthalmopathy, large sphenoid sinus for that age and the coincidental mucocele, the difficulty of operating endoscopically on children.

One of the first points to discuss is the unusually early development of the sphenoid sinus, at age six having almost the dimensions of an adult $(20 / 22 \mathrm{~mm})$ both sphenoid sinuses being well pneumatised.

Particular care should be taken when operating on children, the small nasal fossae and the developing sinuses can be pitfalls even for experienced surgeons. We need to keep in mind that they are not little adults when it comes to nasal and paranasal anatomy and that the anatomy is rather different, with great variability not necessarily linked to the age of the child as in the presented case.

Another important aspect of discussion is the coincidental Graves-like ophthalmopathy, the inflammation which was thought as being related to the sinusal disease, but for which a cause was not determined in spite of immunological, endocrine and bioptyc tests. This raises the problem of the "mirage" of the first lesion, in this particular case the sinusitis was overlapping a possibly autoimmune condition that was manifesting as exophthalmia each time corticosteroid medication was stopped, for the next year after functional endoscopic sinus surgery. This goes to show that the common misconception that, especially in children, the symptomatology is caused by a single illness is to be carefully considered and not taken for granted.

\section{References}

1. Haimi-Cohen, Y., Amir, J., Zeharia, A., Danziger, Y., Ziv, N. \& Mimouni, M. (1999). Isolated sphenoidal sinusitis in children. European journal of pediatrics, 158(4), 298-301.

2. Ai, D., Huang, J., Zhang, H., Huang, M., Chen, M. \& Gao, L. (2011). The diagnosis and management of isolated sphenoiditis in children. Lin chuang er bi yan hou tou jing wai ke za zhi= Journal of clinical otorhinolaryngology, head, and neck surgery, 25(14), 627

3. Hnatuk, L. A., Macdonald, R. E. \& Papsin, B. C. (1994). Isolated sphenoid sinusitis: the Toronto Hospital for Sick Children experience and review of the literature. The Journal of otolaryngology, 23(1), 36

4. Saitoh, A., Beall, B. \& Nizet, V. (2003). Fulminant bacterial meningitis complicating sphenoid sinusitis. Pediatric emergency care, 19(6), 415-417.

5. Radulescu L, Poiata I, Curca I. A. \& Martu D. (2005). Thrombophlebitis of left cavernous sinus secondary to acute right sphenoid sinusitis. Revista Medico-chirurgicala a Societatii de Medici si Naturalisti din Iasi, 109(3):573-576.

6. Herrmann, B. W., White, F. V. \& Forsen, J. W. (2006). Visual loss in a child due to allergic fungal sinusitis of the sphenoid. OtolaryngologyHead and Neck Surgery, 135(2), 328-329.

7. Nemzek, W., Postma, G., Poirier, V. \& Hecht, S. (1995). MR features of pachymeningitis presenting with sixth-nerve palsy secondary to sphenoid sinusitis. American journal of neuroradiology, 16(4), 960-963.

8. Ada, M., Kaytaz, A., Tuskan, K., Güvenç, M. G. \& Selçuk, H. (2004). Isolated sphenoid sinusitis presenting with unilateral VIth nerve palsy. International journal of pediatric otorhinolaryngology, 68(4), 507-510.

9. Turgut, S., Özcan, K. M., Çelikkanat, S. \& Özdem, C. (1997). Isolated sphenoid sinusitis. Rhinology, 35, 132-135

10. Wyllie, J. W., Kern, E. B. \& Djalilian, M. 
(1973). Isolated sphenoid sinus lesions. The Laryngoscope, 83(8), 1252-1265.

11. Deans, J. A. \& Welch, A. R. (1991). Acute isolated sphenoid sinusitis: a disease with complications. The Journal of Laryngology \& Otology, 105(12), 1072-1074 